\title{
Unusual Foreign Body of Sino-orbital Region
}

\author{
Nitin Gupta, Hitesh Verma, Neha Chauhan, Archana Malik, Sarabjit Brar
}

\section{ABSTRACT}

Perforating injuries of the orbit involving the paranasal sinuses are uncommon. We report a case in which a large flat stone foreign body lodged in the anterior orbit and maxillary sinus was surgically removed by a combined approach by otolaryngologist and ophthalmologists.

Keywords: Foreign body, Maxillary sinus, Orbit.

How to cite this article: Gupta N, Verma H, Chauhan N, Malik A, Brar S. Unusual Foreign Body of Sino-orbital Region. Clin Rhinol An Int J 2013;6(3):136-138.

Source of support: Nil

Conflict of interest: None declared

\section{INTRODUCTION}

Management of foreign bodies lodged in the orbit, paranasal sinuses varies according to their size, shape, composition, location and wound of entry. ${ }^{1}$ Only a few cases of nondental paranasal sinus foreign bodies have been reported in the literature. We report a case of sino-orbital foreign body penetrating into the maxillary sinus and anterior orbit and its successful management.

\section{CASE REPORT}

A 42-year-old male presented in Emergency Department of Government Medical College and Hospital, Chandigarh with history of injury over the face when he was sleeping outside and there was a heavy flow of wind due to which he was hit by a concrete block. He complained of loss of vision from left eye and facial disfiguration with a log of concrete impacted over left half of face obscuring the left eye completely (Fig. 1).

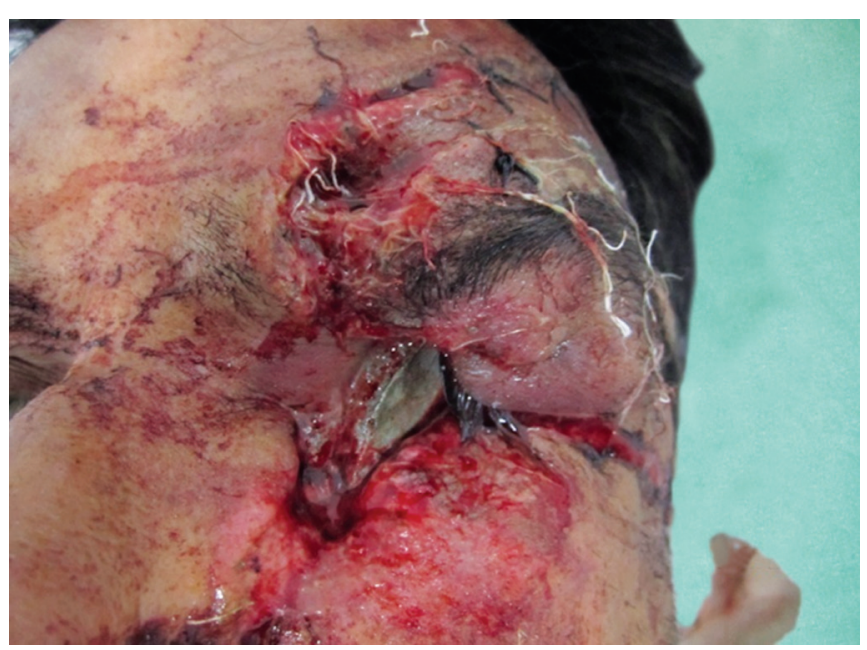

Fig. 1: Lacerated wound with impacted concrete block on left side of face
On examination there was a concrete block presented over the left half of face completely covering the eye ball and the $\log$ penetrated the bones of the face including the left zygoma, maxilla and the nasal bone disfiguring whole of left face. Eye examination showed sunken eyeball and rest of the examination was not possible as the concrete blocked the view. The patient was admitted and NCCT of nose and paranasal sinuses was performed. The NCCT scan showed radiopaque foreign body in left maxillary sinus and orbit. The eye ball was intact and pushed posteriorly (Figs 2A and B).

Patient was shifted to emergency OT for removal of foreign body under GA with a team of otolaryngologists and ophthalmologists. On table examination included log of concrete penetrating then facial bones without affecting the eyeball which remained intact behind. The concrete was penetrating the maxillary bone and reached the nasal bone
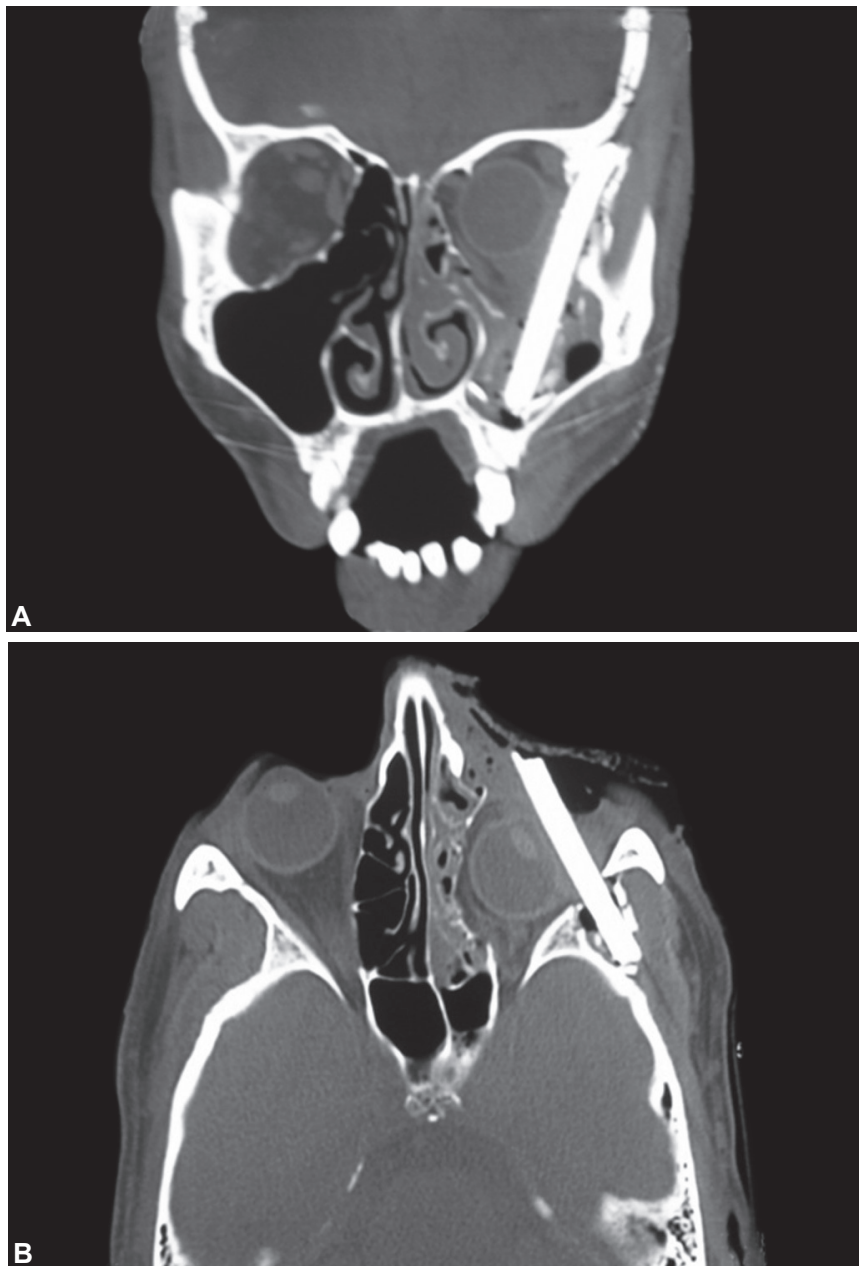

Figs $2 \mathrm{~A}$ and B: NCCT paranasal sinuses and orbit (coronal and axial view) showed radiopaque foreign body extending from left temporal fossa till the floor of left maxillary sinus via orbital outer and inferior wall 
medially, inferiorly till floor of maxillary sinus and body of zygoma laterally.

It was removed from the face after breaking it in piecemeal $(7 \times 5 \mathrm{~cm}$ size) (Figs $3 \mathrm{~A}$ and $\mathrm{B})$.

The eye examination included laceration over the left eyelid which was subsequently sutured, conjunctival hemorrhage with normal cornea. Anterior chamber and posterior chambers and retina were normal. The loss inferior orbit wall was supported by creating hammock sutures. The wound closed in layer. Postoperatively patients the eyeball remained sunken (Fig. 4).

The vision was checked which was 6/18 in left eye. The extraocular movements were within normal limits. The examination on next day showed subluxation of the lens with improvement of vision on follow-up.

\section{DISCUSSION}

The paranasal sinuses are air-filled cavities lined by pseudostratified ciliated epithelium. The maxillary sinus is the largest of the paranasal sinuses. The most commonly found foreign bodies of maxillary sinus are the displaced

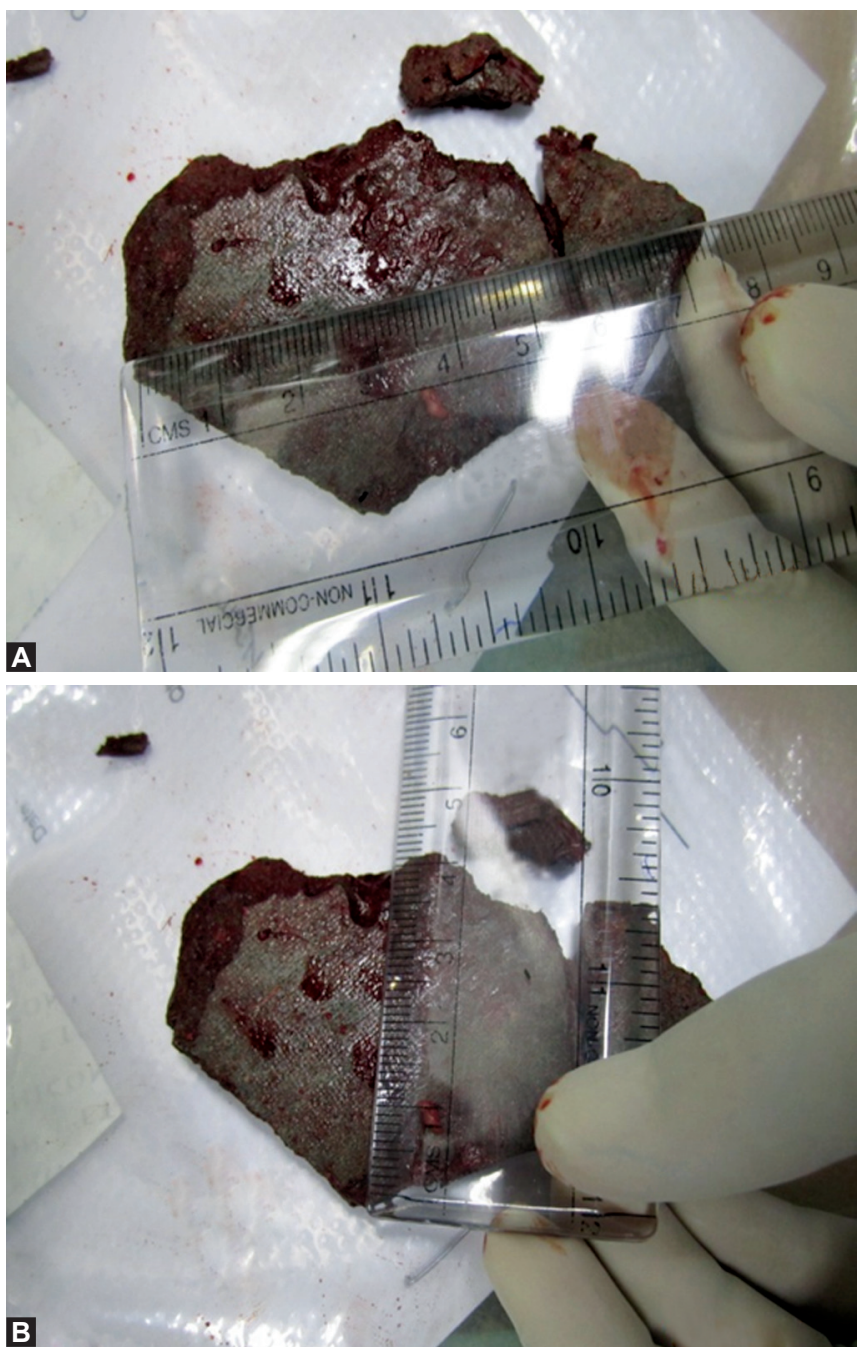

Figs $3 A$ and $B$ : Concrete block $(7 \times 5 \mathrm{~cm})$

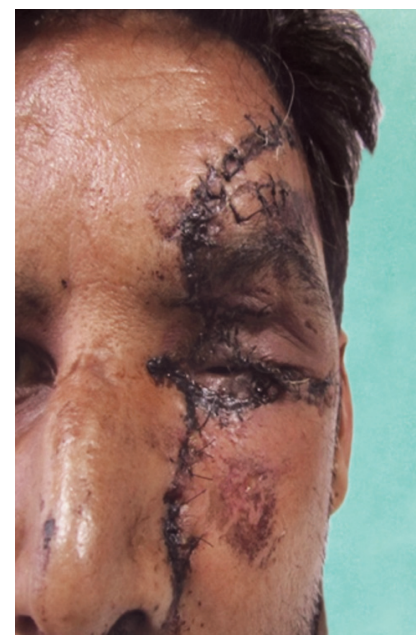

Fig. 4: Postoperative view with shrunken left eye ball

fractured roots of teeth and in some instances displaced whole teeth. ${ }^{2}$ More bizarre foreign bodies include: bullets, ${ }^{3}$ pieces of glass, stones, ${ }^{4}$ wood, ${ }^{5}$ grasses, match sticks ${ }^{6}$ and sand. ${ }^{7}$

In penetrating injuries of the sino-orbital region, imaging has a key role in ruling out foreign bodies, as well as in localization. Computerized tomography scan help in assessment of size, shape of foreign body and involved region, treatment plan. Magnetic resonance imaging ${ }^{8}$ is probably the imaging of choice for wooden foreign bodies. However, in our case CT scan showed foreign body involved anterior part of orbit, maxillary sinus. Foreign bodies that traverse the orbit and the maxillary sinus can be removed transorbitally or though the maxillary sinus, either endoscopically or facial soft tissue approach. Jagannathan et al. ${ }^{9}$ have reported a large metallic foreign body lodged in the infratemporal fossa, maxillary antrum and floor of orbit removed through the maxillary antrum. In our case penetrating wound created by entry of foreign body, was used to remove it. For removal of large foreign bodies of sino-orbital region, team approach involving ENT surgeons, ophthalmologists and if needed neurosurgeons is necessary.

\section{CONCLUSION}

In conclusion, factors like location, size, shape and probable composition of the foreign body need to be considered before making a decision on the appropriate surgical plan. Team approach involving ENT surgeons, ophthalmologists and if needed neurosurgeons is necessary. Appropriate antibiotic cover is paramount in infected cases.

\section{REFERENCES}

1. Tsao YH, Kao CH, Wang HW, Chin SC, Moe KS. Transorbital penetrating injury of paranasal sinuses and anterior skull base by a plastic chair glide: management options of a foreign body in multiple anatomic compartments. Otolaryngol Head Neck Surg 2006;134:177-179. 
2. Worth HM. Principles and practice of oral radiologic interpretation. Chicago: Year Book Medical Publishers Inc 1972:207-212; 700-706.

3. Kozlowski K. Metallic foreign body in the maxillary sinus. Lancet 1965;7361:698.

4. Makino H. A case of foreign body of maxillary sinus which occurred from traumatic injury. J Otolaryngol Jpn 1955;30: 142-145.

5. Tada E, Sato S, Hattori M, Ogawa K, Ootani I. A foreign body of the maxillary sinus with facial fistula. J Otolaryngol Jpn 1967;39:35-39.

6. Rahman A. Foreign bodies in the maxillary antrum. Br Dent J 1982;153:308.

7. Dunagan DP, Cox JE, Chang MC, Haponik EF. Sand aspiration with near- drowning. Radiographic and bronchoscopic findings. Am J Respir Crit Care Med 1997;156:292-295.

8. Specht CS, Varga JH, Jalali MM, Edelstein JP. Orbitocranial wooden foreign body diagnosed by magnetic resonance imaging. Dry wood can be isodense with air and orbital fat by computed tomography. Surv Ophthalmol 1992;36:341-344.

9. Jagannathan M, Nayak BB, Baliarsing AS, Babu ND. An unusual case of orbital trauma with a large foreign body in the maxilla. Br J Plast Surg 1999;52:507-508.

\section{ABOUT THE AUTHORS}

\section{Nitin Gupta}

Assistant Professor, Department of Otolaryngology and Head and Neck Surgery, Government Medical College and Hospital, Chandigarh, India

\section{Hitesh Verma (Corresponding Author)}

Senior Resident, Department of Otolaryngology and Head and Neck Surgery, Government Medical College and Hospital, Chandigarh India, Phone: 91-9417129709, e-mail: drhitesh10@gmail.com

\section{Neha Chauhan}

Junior Resident, Department of Otolaryngology and Head and Neck Surgery, Government Medical College and Hospital, Chandigarh, India

\section{Archana Malik}

Assistant Professor, Department of Ophthalmology, Government Medical College and Hospital, Chandigarh, India

\section{Sarabjit Brar}

Senior Resident, Department of Ophthalmology, Government Medical College and Hospital, Chandigarh, India 